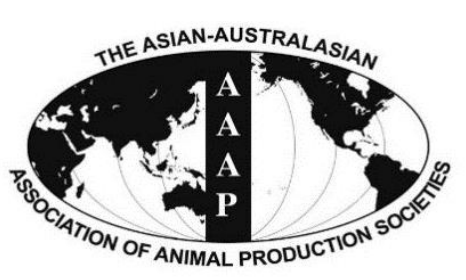

Open Access

Asian Australas. J. Anim. Sci.

Vol. 29, No. 5 : 722-730 May 2016

http://dx.doi.org/10.5713/ajas.15.0303

www.ajas.info

pISSN 1011-2367 elSSN 1976-5517

\title{
Effects of Direct-fed Microbial and Pine Cone Extract on Carcass Traits and Meat Quality of Hanwoo (Korean Native Cattle)
}

\author{
Muhlisin $^{1,2}$, Chang Soo Song ${ }^{3}$, Yong Joon Rhee ${ }^{4}$, Young Han Song ${ }^{5}$, and Sung Ki Lee ${ }^{1, *}$ \\ ${ }^{1}$ Animal Products and Food Science Program, Division of Animal Applied Science, College of Animal Life Sciences, \\ Kangwon National University, Chuncheon 24341, Korea
}

\begin{abstract}
The carcass traits and meat quality of Hanwoo (Korean native cattle) whose diets were supplemented with direct-fed microbial (DFM) and pine cone extract (PCE) were evaluated. Twenty head of Hanwoo steers were divided equally into four groups and for a period of 6 months were given different diets: One group was fed a basal diet as control (CON), the other three groups were fed a basal diet supplemented with DFM-1\%, DFM+PCE-1\% and DFM+PEC-3\%, respectively. DFM+PCE3\% diet resulted the lowest carcass quality grade. The loins of DFM-1\% contained higher moisture and lower fat than did the loins from the CON group. The crude protein content of DFM+PCE-3\% group was significantly higher than that of the other groups. The water holding capacity and Warner-Bratzler shear force of the DFM+PCE-1\% and 3\% groups were lower than those of the CON and DFM-1\% groups. The DFM-1\% and 3\% groups contained lower saturated fatty acid, higher unsaturated fatty acid, mono-unsaturated fatty acid, and poly-unsaturated fatty acid than did $\mathrm{CON}$ and DFM+PCE 1\% group. Moreover, the n6:n3 ratios of DFM-1\% and DFM+PCE-1\% and 3\% groups were slightly lower than that of the CON group. Thus we concluded that DFM and PCE supplementation resulted healthier Hanwoo beef with lower fat content and n6:n3 ratio. (Key Words: Direct-fed Microbial, Hanwoo, Meat Quality, Pine Cone Extract)
\end{abstract}

\section{INTRODUCTION}

Hanwoo beef is renowned for its juiciness, tenderness and flavor. Hanwoo beef is preferred by Korean consumers over imported beef, such as Aberdeen Angus or Holstein steer (Hwang et al., 2010). As such, the price of Hanwoo beef is generally considered to be the highest quality—and often the most expensive - beef in Korea. To maintain and improve the meat quality characteristics of Hanwoo beef, the

\footnotetext{
* Corresponding Author: Sung Ki Lee. Tel: +82-33-250-8646, Fax: +82-33-259-5574, E-mail: skilee@kangwon.ac.kr

${ }^{2}$ Faculty of Animal Science, Universitas Gadjah Mada, Yogyakarta 55281, Indonesia.

${ }^{3}$ Gapyeong Agriculture Technology Center, Gapyeong 12409, Korea.

${ }^{4}$ YJ Co., Ltd., Gapyeong 12402, Korea.

${ }^{5}$ Animal Science Program, Division of Animal Resource Science, College of Animal Life Sciences, Kangwon National University, Chuncheon 24341, Korea.

Submitted Apr. 6, 2015; Revised Jun. 9, 2015; Accepted Dec. 15, 2015
}

feed and feeding management must also be improved. Feed supplementation and additives are often required to increase both the general performance of cattle and the quality of the beef and more specific purposes, such as improving the feed metabolism (Weese et al., 2008).

Probiotics are defined as live microbial feed supplements that provide post-ruminal benefit effects, including the facilitation of beneficial gut microflora establishment and improving its intestinal microbial balance. Because probiotics are composed of a wide variety of viable microbial cultures, culture extracts, enzyme preparations and its combination, thereof the US FDA has required that the term "direct-fed microbial" (DFM) be used in place of 'probiotics' when referring to a source of live, naturally occurring microorganisms (Krehbiel et al., 2003).

According to Weese et al. (2008), supplementing diets with DFM enhances the health status and immune regulation and increases the performance factor of host animals. DFM is also known to exhibit alternative antibiotic characteristics in digestive tracts (Krehbiel et al., 2003). DFM have been 
added as dietary supplements on the feed of cattle (Vyas et al., 2014). Seo et al. (2010) categorized microorganisms used as DFM for ruminants as lactic acid-producing bacteria, such as Lactobacillus, Bifidobacterium, Streptococcus and Enterococcus species; lactic acid-utilizing bacteria, including Megasphaera and Propionibacterium species; yeast and fungi. These bacteria act in both the intestinal tract as well as in the post-gastrointestinal tract. Lactobacillus was found to increased daily weight gain and improved feed efficiency in yearling steers fed a high-concentrate diet compared with control steers (Ware et al., 1988). Bacillus reduces the occurrence of diarrhea in piglets by modulating the immune reaction (Scharek-Tedin et al., 2013). Zerby et al. (2011) demonstrated that Saccharomyces cerevisiae improved the growth and carcass characteristics of lambs and steers. The use of those bacteria as dietary supplements for Hanwoo cattle is, however, remains still limited.

Plant extracts are secondary plant metabolites that may improve animal performance and health when used as effective feed additives for livestock (Liu et al., 2013). Pines (family Pinaceae, genus Pinus) are widely distributed globally around the world and are among the most important forest trees. Plantations of Korean pine (Pinus koraiensis), Japanese red pine (Pinus densiflora) and pitch pine (Pinus rigida) make up major pine plantations in Korea, with production increasing in recent years (Choi et al., 2005). As plantations expand, the production of pine cone, which are normally unused are also growing. Extract from pine cone shaves potential medical benefits for human, such as antitumor, antiviral and immune-potencies for human (Sakagami et al., 1991). Thus, the pine cone extract (PCE) may also be the effective dietary supplements for cattle.

Many studies have examined the effect of DFM supplementation and natural feed additives on the performance of live cattle and on carcass quality. To our knowledge, however, studies examining the effect of DFM and natural feed additives on meat are largely lacking. This research was conducted in order to evaluate the effect of dietary supplementation of DFM and PCE on the quality of Hanwoo cattle.

\section{MATERIALS AND METHODS}

\section{Probiotic and diets}

The direct-fed microbial/DFM used in this study contained Bacillus subtilis $\left( \pm 1.7 \times 10^{7} \log\right.$ colony-forming unit [cfu]), Lactobacillus plantarum $\left( \pm 1.3 \times 10^{7} \log \mathrm{cfu}\right)$ and Saccharomyces cerevisiae $\left( \pm 7.5 \times 10^{7} \log \mathrm{cfu}\right)$. Two mixtures were formulated: the first consisting of 5\% DFM, $70 \%$ growth media (corn, soybean hulls and barley) and $25 \%$ water (DFM), and the second consisting of 5\% DFM, 70\% growth media, $12.5 \%$ water and $12.5 \%$ of aqueous pine cone extract (DFM+PCE). The PCE was obtained via stem extraction. Probiotic mixtures was fermented at room temperature $\left( \pm 25^{\circ} \mathrm{C}\right)$ for $48 \mathrm{~h}$ until the moisture content reached $12 \%$. The feed compositions are presented in Table 1.

\section{Experimental animals}

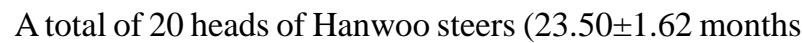
old) were randomly assigned to four different diets with feeding restriction system, with each group consisting of four animals. The average initial body weight was $592.20 \pm 69.13$ $\mathrm{kg}$. The control group (CON) was fed basal diet devoid of DFM, and the three other groups were fed basal diet supplemented with DFM-1\%, DFM+PCE-1\% or DFM+PCE-3\%, respectively. Animals within the same group were raised in a $5 \times 10 \mathrm{~m}$ pen on a farm located in the Gapyeong Agricultural Technology Center in Kyeonggi Province, South Korea. Feed intake and growth performance are shown in Table 2. After 6 months of feeding period, the animals were slaughtered in the Nonghyup Bucheon slaughtering house in Bucheon city, South Korea. The carcasses were weighed and then chilled at $2{ }^{\circ} \mathrm{C} \pm 2{ }^{\circ} \mathrm{C}$ for 24 $\mathrm{h}$ in chilling room. Carcass traits were estimated using the

Table 1. Ingredient and chemical composition of formula feed (DM basis)

\begin{tabular}{lc}
\hline Items & $\%$ \\
\hline Ingredient & 32.4 \\
Corn grain & 7.5 \\
Wheat grain & 2.5 \\
Wheat flour & 13.0 \\
Wheat bran & 10.0 \\
Corn gluten feed & 5.0 \\
Tapioca pellet & 1.0 \\
Soybean meal & 2.7 \\
Soybean hull & 10.0 \\
Coconut meal & 3.2 \\
DDGS & 3.0 \\
Malt cake & 4.0 \\
Cane molasses & 2.0 \\
Limestone & 0.8 \\
Salt & 2.9 \\
Trace materials & \\
Chemical composition, $\%$ DM & 89.59 \\
DM & 12.32 \\
Crude protein & 5.01 \\
Ether extract & 5.00 \\
Crude fiber & 6.05 \\
Crude ash & 61.21 \\
NFE & 0.72 \\
Ca & 0.53 \\
TDN & 71.94 \\
\hline DM & \\
\hline
\end{tabular}

DM, dry matter; DDGS, dried distillers grains with soluble; NFE, nitrogenfree extract; TDN, total digestible nutrients. 
Table 2. Feed intake and growth performance

\begin{tabular}{|c|c|c|c|c|}
\hline & \multicolumn{4}{|c|}{ Treatments $^{1}$} \\
\hline & $\mathrm{CON}$ & DFM $1 \%$ & DFM+PCE $1 \%$ & DFM+PCE 3\% \\
\hline \multicolumn{5}{|c|}{ Daily feed intake (kg/head) } \\
\hline Concentrate & 8.00 & 7.92 & 7.92 & 7.76 \\
\hline DFM & - & 0.08 & - & - \\
\hline $\mathrm{DFM}+\mathrm{PCE}$ & - & - & 0.08 & 0.24 \\
\hline Rice straw & 1.00 & 1.00 & 1.00 & 1.00 \\
\hline \multicolumn{5}{|c|}{ Growth performance $(\mathrm{kg})^{2}$} \\
\hline Final body weight & $721.31 \pm 50.14^{\mathrm{a}}$ & $712.59 \pm 78.22^{\mathrm{a}}$ & $658.38 \pm 30.55^{\mathrm{b}}$ & $669.75 \pm 68.33^{\mathrm{ab}}$ \\
\hline Daily gain & $0.57 \pm 0.25^{\mathrm{a}}$ & $0.38 \pm 0.19^{b}$ & $0.61 \pm 0.15^{\mathrm{a}}$ & $0.63 \pm 0.16^{\mathrm{a}}$ \\
\hline
\end{tabular}

Korean carcass grading system (KAPE, 2010). Parameters used to determine yield grade (hot carcass weight, backfat thickness and ribeye area) and quality grade (marbling score) were recorded. The loins (longissimus dorsi 1st lumbar vertebrae) were obtained, vacuum-packed, placed in an ice box and transported to Meat Science Laboratory at Kangwon National University. The loins were divided into two parts; the first part was stored at $-70^{\circ} \mathrm{C}$ for proximate and fatty acid composition analyses and the second part was used for meat quality analyses.

\section{Proximate analysis}

The frozen beef were allowed to thaw overnight at $4{ }^{\circ} \mathrm{C}$ prior to the meat quality analyses. The proximate analyses, including moisture, crude protein, crude fat and ash content, were performed according to methods outlined by the Association of Official Analytical Chemists methods (AOAC, 2007).

\section{pH and instrumental color}

The $\mathrm{pH}$ of meat slurry was measured at room temperature using a $\mathrm{pH}$ meter (SevenEasy $\mathrm{pH}$, Mettler-Toledo $\mathrm{GmbH}$, Giessen, Switzerland). A $10 \mathrm{~g}$ of each sample was homogenized with $100 \mathrm{~mL}$ of distilled water at $10,000 \mathrm{rpm}$ for $60 \mathrm{~s}$ using a homogenizer (PH91, SMT Co. Ltd., Tokyo, Japan). The instrumental Commission internationale de l'éclairage (CIE) color of samples, including lightness (CIE $\left.\mathrm{L}^{*}\right)$, redness (CIE $\mathrm{a}^{*}$ ), yellowness (CIE b*), chroma and hue angle, were measured using a color difference meter (CR400, Konica Minolta Sensing Inc., Tokyo, Japan). The color meter was standardized using a white plate (Illuminant $\mathrm{C}$ : Y $=93.6, \mathrm{x}=0.3134$, and $\mathrm{y}=0.3194)$. Ten times random measurements were taken for each sample.

\section{Total myoglobin content}

Total myoglobin content was analyzed according to the procedure described in Sammel et al. (2002). First, $5 \mathrm{~g}$ of each sample was homogenized with $15 \mathrm{~mL}$ of cold distilled water using a homogenizer (UltraTurrax T25 basic, IkaWerke GmbH and Co., Staufen, Germany) at 13,000 rpm for $10 \mathrm{~s}$. The homogenate was kept at $4{ }^{\circ} \mathrm{C}$ for an hour, then was centrifuged at $10,000 \times g$ for $30 \mathrm{~min}$ using a rotor JA-20 (Beckman Instruments, Inc., Palo Alto, CA, USA). and a centrifuge J2-21 (Beckman Instruments, Inc., USA). Supernatant was filtered through 0.45 syringe filter (Hydrophilic PTFE, Adventec MFS, Inc., Dublin, CA, USA). The absorbance of the supernatant was measured at a wavelength of $525 \mathrm{~nm}$ using a spectrophotometer (UV-mini1240, Shimadzu, Kyoto, Japan).

\section{Water holding capacity and cooking loss}

The water holding capacity (WHC) was performed according to filter paper-pressed method described by Grau and Hamm (1953), whereby $0.3 \mathrm{~g}$ of each samples was weighed on a Whatman filter paper (No. 2), and then the samples were pressed between 2 plexiglass plates for $5 \mathrm{~min}$. The areas of pressed sample and water were measured using a planimeter (Super Planix $\alpha$, Tamaya Technics Inc., Tokyo, Japan). The WHC was calculated as follows:

$$
\text { WHC }(\%)=\frac{\text { area of sample }(\text { meat })}{\text { area of water }} \times 100 \%
$$

To determine the cooking loss, $100 \mathrm{~g}$ of sample were boiled individually in polyethylene bags immersed in an $80^{\circ} \mathrm{C}$ water bath for $30 \mathrm{~min}$, and then removed and allowed to cool. The samples were cooled for an additional $30 \mathrm{~min}$. The initial weights of uncooked and cooked meat were recorded, and the cooking loss was calculated as follows:

Cooking loss $(\%)=\frac{W u-W c}{W u} \times 100 \%$

$\mathrm{Wu}=$ Weight of uncooked meat $(\mathrm{g})$

$\mathrm{Wc}=$ Weight of cooked meat $(\mathrm{g})$ 


\section{Warner-Blatzer shear force and texture profile analysis}

Cooked sample (following cooking loss determination) were cut into cubes $(1 \times 1 \times 1 \mathrm{~cm})$, and Warner-Blatzer shear force (WBSF) and texture profile analysis (TPA) were measured using a texture analyzer (TA-XT2 $i$ version 6.06, Stable Micro Systems Ltd., Surrey, UK). The TPA parameters included hardness, adhesiveness, springiness, gumminess, chewiness, cohesiveness, and resilience and were measured twice at $70 \%$ compression with a pre-test speed $1.0 \mathrm{~mm} / \mathrm{s}$, a test speed $1.0 \mathrm{~mm} / \mathrm{s}$ and a posttest speed of $5.0 \mathrm{~mm} / \mathrm{s}$, with a $2 \mathrm{~s}$ rest period between two cycles. Ten measurements were performed on the meat of each of 16 head of cattle.

\section{Thiobarbituric acid reactive substances}

Thiobarbituric acid reactive substances (TBARS) value was measured according to the procedure outlined by Sinnhuber and Yu (1977), whereby $0.5 \mathrm{~g}$ of ground beef were mixed with 3 drops of antioxidant solution (3\% butylated hydroxyanisole-54\% propylene glycol-3\% butylated hydroxytoluene-40\% Tween 20 ), $3 \mathrm{~mL}$ of thiobarbituric acid solution (1\% 4,6-Dihydroxy-2-mercaptopyrimidine), and 17 $\mathrm{mL}$ of $25 \%$ trichloroacetic acid. The mixture was heated at $100^{\circ} \mathrm{C}$ for $30 \mathrm{~min}$ and then, centrifuged at $3,000 \times g$ for $30 \mathrm{~min}$. An absorbance of supernatant was measured at a wavelength of $532 \mathrm{~nm}$ using a spectrophotometer (UV-mini-1240, Shimadzu, Japan). The results were calculated as $\mathrm{mg}$ malonaldehyde per kg sample. A total of four measurements were performed on each samples.

\section{Fatty acid composition}

Lipids of samples were extracted from the samples using the methods described by Folch et al. (1957), in which $5 \mathrm{~g}$ of each sample was homogenized with $25 \mathrm{~mL}$ of chloroform:methanol $(2: 1, \mathrm{v} / \mathrm{v})$ at $13,500 \mathrm{rpm}$ using a homogenizer (Ultra Turax T25 basic, Ika WerkeGmbh \& Co., Staufen, Germany). The homogenates were added with $0.88 \%$ of $\mathrm{KCl}$ and then were centrifuged at $3,000 \times \mathrm{g}$ for $10 \mathrm{~min}$. The supernatant was evaporated at $38^{\circ} \mathrm{C}$ on an $\mathrm{N}_{2}$ gas blowing concentrator (MG 2200, Eyela Co., Tokyo, Japan). The methylation was performed according to procedure set out by AOAC (2007). Briefly, $200 \mu \mathrm{L}$ extracted lipid and $2 \mathrm{~mL}$ of 2 $\mathrm{N} \mathrm{NaOH}$ were vortex-mixed and heated at $80^{\circ} \mathrm{C}$ for $60 \mathrm{~min}$. The samples were cooled by immersing in cold water, vortex-mixed with $2 \mathrm{~mL}$ of $25 \% \mathrm{BF}_{3}-\mathrm{MeOH}$, heated again at $80^{\circ} \mathrm{C}$ for $60 \mathrm{~min}$. After cooling for $10 \mathrm{~min}$ in cold water, the samples were mixed again with $3 \mathrm{~mL}$ of distilled water and $2 \mathrm{~mL}$ of hexane, vortexed and centrifuged at $3,000 \times \mathrm{g}$ for 10 min. About $1.5 \mathrm{~mL}$ of the upper layer was collected and moved into vials. The fatty acid composition of each sample was analyzed using an Agilent $6890 \mathrm{~N}$ (Agilent Technologies, Inc., Santa Clara, CA, USA) equipped with the automatic sampler Agilent 7683 (Agilent Technologies, Inc., USA) and an HP-Innowax column ( $30 \mathrm{~m}$ length $\times 0.32 \mathrm{~mm}$ i.d. $\times 0.25$ $\mu \mathrm{m}$ film thickness; Agilent Technologies, Inc., USA). One microliter of sample was injected (split $1: 10 ; 260^{\circ} \mathrm{C}$ ) and then was carried out at a flow rate of $1.0 \mathrm{~mL} / \mathrm{min}$ using helium. Oven temperatures were set at $150^{\circ} \mathrm{C}$ for $1 \mathrm{~min}$, $150^{\circ} \mathrm{C}$ to $200^{\circ} \mathrm{C}$ at $15^{\circ} \mathrm{C} / \mathrm{min}, 200^{\circ} \mathrm{C}$ to $250^{\circ} \mathrm{C}$ at $3^{\circ} \mathrm{C} / \mathrm{min}$, and $250^{\circ} \mathrm{C}$ for $5 \mathrm{~min}$. The flame ionization detector was set at $280^{\circ} \mathrm{C}$. The fatty acid peaks were identified and quantified by comparison with the retention time and peak area of fatty acid standards (47015-U, Supelco Analytical, Bellefonte, PA, USA).

\section{Statistical analysis}

Data were analyzed using SPSS statistic 19.0 for Windows Evaluation Version (2010). One-way analysis of variance followed by Duncan's multiple range tests were used to determine statistical significance among the means at 95\% significance level.

\section{RESULTS}

Table 2 shows that by daily restriction feeding of each diet of $9 \mathrm{~kg}$, the final body weight of DFM+PCE1\% and $\mathrm{DFM}+\mathrm{PCE} 3 \%$ groups were lower than that of CON and DFM1\% groups. However, the average daily gain of DFM1\% group was the lowest among other diet groups. DFM+PCE supplementation up to $3 \%$ did not affect average daily gain of Hanwoo steers during finishing period.

The means of carcass traits of Hanwoo cattle fed with DFM and PCE are shown in Table 3. Supplementation of $\mathrm{DFM}+\mathrm{PCE} 3 \%$ resulted higher hot carcass weight and larger rib eye area than that of DFM+PCE1\% group, however both treatments had lower mean values than CON and DFM1\% groups. No significant differences were found among diet groups on back fat thickness. The lowest average marbling score was found on DFM+PCE3\% group, showing the leanest loin among other diet groups, while DFM+PCE1\% group had better marbling score than DFM1\% group. The yield index and grade were not different among diet groups. CON group had the highest quality grade followed by $\mathrm{DFM}+\mathrm{PCE} 1 \%$, DFM1\%, and DFM+PCE3\% groups.

Table 4 summarizes the proximate analysis and quality characteristics data of DFM and PCE supplemented Hanwoo beef. No differences for crude ash content, cooking loss and myoglobin content were detected among the treatments. Hanwoo cattle fed diet supplemented with DFM-1\% and $\mathrm{DFM}+\mathrm{PCE}-1 \%$ and $3 \%$ had higher moisture and lower fat contents compared with the control groups. DFM+PCE-1\% and $3 \%$ supplementation tended to improve the crude protein content of the meat; whereas the DFM+PCE-3\% groups was significantly higher than that of the other groups.

The $\mathrm{pH}$ of all groups is ranged from 5.49 to 5.60. The WHC of DFM+PCE-1\% and $3 \%$ groups were significantly 
Table 3. Carcass traits of Hanwoo cattle fed a diet supplemented with DFM and PCE

\begin{tabular}{|c|c|c|c|c|}
\hline \multirow{2}{*}{ Parameters } & \multicolumn{4}{|c|}{ Treatments $^{1}$} \\
\hline & $\mathrm{CON}$ & DFM-1\% & DFM+PCE-1\% & DFM+PCE-3\% \\
\hline Hot carcass weight $(\mathrm{kg})$ & $421.40 \pm 31.00^{\mathrm{a}}$ & $430.80 \pm 47.60^{\mathrm{a}}$ & $387.60 \pm 14.08^{\mathrm{b}}$ & $412.60 \pm 44.15^{\mathrm{ab}}$ \\
\hline Ribeye area $\left(\mathrm{cm}^{2}\right)$ & $92.60 \pm 9.15^{\mathrm{a}}$ & $89.40 \pm 3.78^{\mathrm{a}}$ & $81.00 \pm 7.31^{\mathrm{b}}$ & $86.80 \pm 6.61^{\mathrm{ab}}$ \\
\hline Backfat thickness (mm) & $14.20 \pm 4.15$ & $11.40 \pm 5.94$ & $15.80 \pm 4.97$ & $12.60 \pm 2.88$ \\
\hline Marbling score ${ }^{2}$ & $7.00 \pm 1.22^{\mathrm{a}}$ & $5.00 \pm 1.00^{\mathrm{bc}}$ & $6.00 \pm 2.12^{\mathrm{ab}}$ & $4.20 \pm 1.10^{\mathrm{c}}$ \\
\hline Yield index ${ }^{3}$ & $64.46 \pm 3.35$ & $65.57 \pm 3.30$ & $62.76 \pm 3.67$ & $64.91 \pm 2.21$ \\
\hline Yield grade $^{4}$ & $1.80 \pm 0.84$ & $2.20 \pm 0.84$ & $1.60 \pm 0.55$ & $2.00 \pm 0.71$ \\
\hline Quality grade ${ }^{5}$ & $4.20 \pm 0.84^{\mathrm{a}}$ & $3.40 \pm 0.55^{\mathrm{bc}}$ & $3.80 \pm 0.84^{\mathrm{ab}}$ & $3.00 \pm 0.71^{\mathrm{c}}$ \\
\hline
\end{tabular}

Values are expressed as the mean \pm standard deviation.

${ }^{1} \mathrm{CON}$, control; DFM-1\%, $1 \%$ direct-fed microbial supplementation; DFM+PCE-1\% and 3\%, $1 \%$ and $3 \%$ direct-fed microbial added with pine cone extract supplementation.

${ }^{2}$ Marbling score standard; No.1-No.9 (1 = devoid, 9 = abundant).

${ }^{3}$ Yield index $=65.834-[0.393 \times$ backfat thickness $(\mathrm{mm})]+\left[0.088 \times\right.$ ribeye area $\left.\left(\mathrm{cm}^{2}\right)\right]-[0.008 \times$ hot carcass weight $(\mathrm{kg})]+2.01$.

${ }^{4}$ A grade (yield index $\left.\geq 69.00\right)=3$, B grade $(66.00 \leq$ yield inde $<69.00)=2, \mathrm{C}$ grade $($ yield index $<66.00)=1$.

${ }^{5} 1++$ grade $=5,1+$ grade $=4,1$ grade $=3,2$ grade $=2,1$ grade $=1$.

Different superscripts indicate significant differences $(a>b>c, p<0.05)$.

lower than those of the CON and DFM-1\% groups but WHC between the CON and DFM-1\% was not significantly different. The lowest TBARS value derived from the DFM+PCE-3\% $\quad(\mathrm{p}<0.05)$ groups; with no significant difference in TBARS value was observed among the other three groups.

Table 5 shows the instrumental color of Hanwoo loin taken from cattle whose diet was supplemented with DFM and PCE. Dietary supplementation with DFM significantly reduced the CIE L* of loin $(\mathrm{p}<0.05)$. The presence or absence of PCE had no effect on the color differential. No significant difference in CIE $\mathrm{a}^{*}, \mathrm{CIE} \mathrm{b}^{*}$ and chroma were found between $\mathrm{CON}$ and treatment groups.

The results of the TPA and texture obtained with WBSF analyses are presented in Table 6. No differences in fractuability, adhesiveness, cohesiveness and resilience of TPA were found among the experimental groups, and no difference was found in the WBSF value between CON and
DFM-1\% groups. The hardness (TPA) of the CON group was lower than that of the three treatment groups. The loins of Hanwoo fed DFM- or DFM+PCE-supplemented diets had higher gumminess and chewiness compared to CON group $(\mathrm{p}<0.05)$. However, there was no difference in hardness, gumminess and chewiness among the DFM and DFM+PCE$1 \%$ and $3 \%$ groups ( $>>0.05)$.

Fatty acid compounds of Hanwoo fed a diet supplemented with DFM and CPE are presented in Table 7. Palmitic and oleic acid were the primary fatty acid compounds found in the Hanwoo beef examined in the present study. No difference in palmitoleic acid, oleic acid, vaccenic acid, alpha-linolenic acid, cis-eicosonic acid and arachidonic acid was found among the treatment groups $(p>0.05)$. The total saturated fatty acid (SFA), unsaturated fatty acid (UFA), mono-unsaturated fatty acid (MUFA), and poly-unsaturated fatty acid (PUFA) of the DFM- $1 \%$ and $\mathrm{DFM}+\mathrm{PCE}-3 \%$ groups were higher than those of $\mathrm{CON}$ and

Table 4. Proximate and quality characteristics of beef from Hanwoo cattle fed a diet supplemented with DFM and PCE

\begin{tabular}{|c|c|c|c|c|}
\hline \multirow{2}{*}{ Parameters } & \multicolumn{4}{|c|}{ Treatments $^{1}$} \\
\hline & $\mathrm{CON}$ & DFM $1 \%$ & DFM+PCE $1 \%$ & DFM+PCE 3\% \\
\hline \multicolumn{5}{|l|}{$\overline{\text { Proximate (\%) }}$} \\
\hline Moisture & $59.03 \pm 1.49^{\mathrm{b}}$ & $64.94 \pm 3.73^{\mathrm{a}}$ & $62.18 \pm 3.88^{\mathrm{a}}$ & $64.05 \pm 2.23^{\mathrm{a}}$ \\
\hline Crude ash & $0.88 \pm 0.21$ & $0.93 \pm 0.12$ & $0.86 \pm 0.13$ & $0.79 \pm 0.14$ \\
\hline Crude protein & $18.48 \pm 1.25^{\mathrm{b}}$ & $18.77 \pm 0.81^{\mathrm{b}}$ & $19.40 \pm 2.48^{\mathrm{ab}}$ & $20.97 \pm 1.96^{\mathrm{a}}$ \\
\hline Crude fat & $21.61 \pm 2.26^{\mathrm{a}}$ & $15.36 \pm 5.88^{\mathrm{b}}$ & $17.56 \pm 5.41^{\mathrm{ab}}$ & $14.19 \pm 3.02^{b}$ \\
\hline $\mathrm{pH}$ & $5.49 \pm 0.03^{b}$ & $5.60 \pm 0.05^{\mathrm{a}}$ & $5.49 \pm 0.03^{b}$ & $5.56 \pm 0.03^{\mathrm{a}}$ \\
\hline WHC (\%) & $54.29 \pm 9.68^{\mathrm{a}}$ & $53.01 \pm 7.63^{\mathrm{a}}$ & $45.34 \pm 5.22^{\mathrm{b}}$ & $45.01 \pm 2.70^{\mathrm{b}}$ \\
\hline Cooking loss (\%) & $25.95 \pm 2.85$ & $22.95 \pm 3.64$ & $25.46 \pm 2.46$ & $25.74 \pm 1.49$ \\
\hline Myoglobin (mg/g) & $5.61 \pm 0.87$ & $6.68 \pm 0.60$ & $6.58 \pm 0.86$ & $6.45 \pm 0.60$ \\
\hline TBARS (mg MA/kg) & $0.68 \pm 0.13^{\mathrm{a}}$ & $0.61 \pm 0.08^{\mathrm{ab}}$ & $0.66 \pm 0.11^{\mathrm{a}}$ & $0.54 \pm 0.09^{b}$ \\
\hline
\end{tabular}

WHC, water holding capacity; TBARS, thiobarbituric acid reactive substances; MA, malonaldehyde.

Values are expressed as the mean \pm standard deviation.

Different superscripts indicate significant differences $(\mathrm{a}>\mathrm{b}>\mathrm{c}, \mathrm{p}<0.05)$.

${ }^{1}$ CON, control; DFM-1\%, $1 \%$ direct-fed microbial supplementation; DFM+PCE-1\% and 3\%, $\%$ and 3\% direct-fed microbial added with pine cone extract supplementation. 
Table 5. Instrumental color of beef from Hanwoo cattle fed a diet supplemented with DFM and PCE

\begin{tabular}{|c|c|c|c|c|}
\hline \multirow{2}{*}{ Parameters } & \multicolumn{4}{|c|}{ Treatments $^{1}$} \\
\hline & $\mathrm{CON}$ & DFM-1\% & DFM+PCE-1\% & DFM+PCE-3\% \\
\hline Lightness (CIE L*) & $44.99 \pm 3.56^{\mathrm{a}}$ & $42.34 \pm 2.96^{\mathrm{b}}$ & $43.17 \pm 3.87^{b}$ & $43.43 \pm 2.19^{b}$ \\
\hline Redness (CIE a*) & $20.73 \pm 2.37$ & $21.04 \pm 2.89$ & $20.36 \pm 2.64$ & $21.02 \pm 1.81$ \\
\hline Yellowness (CIE b*) & $10.63 \pm 1.45$ & $10.29 \pm 1.88$ & $10.18 \pm 1.54$ & $10.45 \pm 1.26$ \\
\hline Chroma $\left(\mathrm{C}^{*}\right)$ & $23.33 \pm 2.70$ & $23.43 \pm 3.40$ & $22.78 \pm 2.98$ & $23.48 \pm 2.14$ \\
\hline Hue angle $\left(h^{\circ}\right)$ & $26.96 \pm 1.77^{\mathrm{a}}$ & $25.90 \pm 1.54^{\mathrm{b}}$ & $26.42 \pm 1.79^{\mathrm{ab}}$ & $26.38 \pm 1.30^{\mathrm{ab}}$ \\
\hline
\end{tabular}

CIE, Commission Internationale de l'éclairage.

Values are expressed as the mean \pm standard deviation.

${ }^{1} \mathrm{CON}$, control; DFM-1\%, $1 \%$ direct-fed microbial supplementation; DFM+PCE-1\% and 3\%, $1 \%$ and $3 \%$ direct-fed microbial added with pine cone extract supplementation.

Different superscripts indicate significant differences $(a>b>c, p<0.05)$.

DFM+PCE-1\% groups. Moreover, the n6:n3 ratios of the DFM and DFM+PCE- $1 \%$ and $3 \%$ were slightly lower than that of the CON group.

\section{DISCUSSION}

The effect of DFM and PCE inclusion in the finishing diet of Hanwoo steers significantly appeared on growth performance, particularly average daily gain. Because the differences on final body weight were merely caused by different age. CON and DFM1\% groups consisted of Hanwoo steers that were one month older than DFM+PCE$1 \%$ and $3 \%$ groups. It can be seen by large variation on initial age. Our result of supplementation of DFM1\% alone without PCE was not in line with previous finding (Vyas et al., 2014). Sex and diet may be responsible for this reason. However, DFM+PCE groups did not show any differences. Different age also affected hot carcass weight and rib eye area. Although DFM+PCE3\% diet resulted the lowest carcass quality grade, our results suggest that the healthier beef can be produced by the supplementation of DFM+PCE3\% during fattening period. Hanwoo cattle fed a diet supplemented with DFM-1\% and DFM+PCE-1\% and 3\% had higher moisture and a lower fat content compared with the control groups. Breed type and diet are major factors influencing lipid deposition in meat (Costa et al., 2013); our results suggest that DFM and PCE supplementation decreased the fat deposition in muscle. DFM supplementation alone (i.e., without PCE) did not improve crude protein content. However, the inclusion of DFM+PCE-1\% and 3\% tended to improve the crude protein content of the meat; the crude protein content of the DFM+PCE-3\% groups was significantly higher than that of the other groups. It would appear that the proximate quality of Hanwoo cattle whose dietary was supplemented with DFM+PCE-3\% had better proximate content than did the other groups due to the lower fat and higher protein contents of its beef. Meat with lower fat and higher protein contents are generally regarded as being healthier for consumers. The inclusion DFM and bioactive compounds from PCE on ruminant's diet may affect rumen microbiome, fermentation, and biohydrogenation, where starch levels on fattening diet supports the growth of lactic acid bacteria and yeast used in this study. Musso et al. (2010) highlighted that gut

Table 6. Warner-Blatzer shear force (WBSF; kg) and texture profile analysis (TPA) of beef from Hanwoo cattle fed a diet supplemented with DFM and PCE

\begin{tabular}{lcccc}
\hline \multirow{2}{*}{ Parameters } & \multicolumn{3}{c}{ Treatments $^{1}$} \\
\cline { 2 - 5 } & CON & DFM- $\%$ & DFM+PCE- $\%$ & DFM+PCE-3\% \\
\hline WBSF (kg) & $4.25 \pm 1.19^{\mathrm{a}}$ & $4.41 \pm 1.31^{\mathrm{a}}$ & $3.74 \pm 1.19^{\mathrm{b}}$ & $3.85 \pm 0.69^{\mathrm{b}}$ \\
TPA & & & $6.01 \pm 0.55^{\mathrm{b}}$ \\
Hardness (kg) & $7.84 \pm 1.97^{\mathrm{a}}$ & $6.88 \pm 0.98^{\mathrm{ab}}$ & $6.08 \pm 1.04^{\mathrm{b}}$ & $0.02 \pm 0.00$ \\
Fractuability & $0.02 \pm 0.00$ & $0.02 \pm 0.00$ & $0.02 \pm 0.00$ & $-0.03 \pm 0.03$ \\
Adhesiveness & $-0.01 \pm 0.01$ & $-0.03 \pm 0.00$ & $-0.01 \pm 0.01$ & $0.51 \pm 0.04$ \\
Springiness & $0.54 \pm 0.03$ & $0.48 \pm 0.06$ & $0.53 \pm 0.07$ & $0.32 \pm 0.04$ \\
Cohesiveness & $0.30 \pm 0.03$ & $0.30 \pm 0.06$ & $0.29 \pm 0.04$ & $5.57 \pm 1.41^{\mathrm{a}}$ \\
Gumminess & $2.39 \pm 0.75^{\mathrm{b}}$ & $4.59 \pm 1.52^{\mathrm{a}}$ & $4.77 \pm 1.67^{\mathrm{a}}$ & $2.87 \pm 0.79^{\mathrm{a}}$ \\
Chewiness & $1.27 \pm 0.36^{\mathrm{b}}$ & $2.23 \pm 0.84^{\mathrm{a}}$ & $2.45 \pm 1.74^{\mathrm{a}}$ & $0.14 \pm 0.03$ \\
Resilence $(\mathrm{mm})$ & $0.13 \pm 0.02$ & $0.13 \pm 0.03$ & $0.12 \pm 0.02$ & \\
\hline
\end{tabular}

Values are expressed as the mean \pm standard deviation.

${ }^{1} \mathrm{CON}$, Control; DFM-1\%, $1 \%$ direct-fed microbial supplementation; DFM+PCE-1\% and 3\%, $1 \%$ and 3\% direct-fed microbial added with pine cone extract supplementation.

Different superscripts indicate significant differences $(a>b>c, p<0.05)$. 
Table 7. Fatty acid compounds of beef from Hanwoo cattle fed a diet supplemented with DFM and PCE

\begin{tabular}{|c|c|c|c|c|}
\hline \multirow{2}{*}{ Fatty acids } & \multicolumn{4}{|c|}{ Treatments $^{1}$} \\
\hline & $\mathrm{CON}$ & DFM-1\% & DFM+PCE-1\% & DFM+PCE-3\% \\
\hline$\overline{\mathrm{C} 14: 0}$ & $3.49 \pm 0.48^{\mathrm{ab}}$ & $2.94 \pm 0.59^{b}$ & $4.03 \pm 0.67^{\mathrm{a}}$ & $3.13 \pm 0.38^{\mathrm{ab}}$ \\
\hline C16:0 & $28.71 \pm 1.20^{\mathrm{a}}$ & $24.76 \pm 2.15^{\mathrm{b}}$ & $29.72 \pm 1.89^{\mathrm{a}}$ & $25.79 \pm 0.55^{\mathrm{b}}$ \\
\hline $\mathrm{C} 16: 1 \mathrm{n} 7$ & $5.34 \pm 1.08$ & $5.61 \pm 0.79$ & $5.75 \pm 1.07$ & $4.84 \pm 0.79$ \\
\hline C18:0 & $17.05 \pm 0.05^{\mathrm{b}}$ & $19.79 \pm 2.72^{\mathrm{a}}$ & $17.72 \pm 1.59^{\mathrm{b}}$ & $18.85 \pm 2.67^{a}$ \\
\hline C18:1n9 & $41.45 \pm 2.24$ & $42.16 \pm 1.53$ & $38.60 \pm 2.10$ & $41.84 \pm 2.74$ \\
\hline C18:1n7 & $0.15 \pm 0.01$ & $0.26 \pm 0.15$ & $0.49 \pm 0.29$ & $0.35 \pm 0.19$ \\
\hline C18:2n6 & $2.89 \pm 0.43^{\mathrm{ab}}$ & $3.05 \pm 1.02^{\mathrm{ab}}$ & $2.54 \pm 0.58^{b}$ & $3.74 \pm 1.24^{\mathrm{a}}$ \\
\hline C18:3n6 & $0.15 \pm 0.03^{b}$ & $0.35 \pm 0.08^{\mathrm{a}}$ & $0.18 \pm 0.11^{\mathrm{b}}$ & $0.32 \pm 0.03^{\mathrm{a}}$ \\
\hline $\mathrm{C} 18: 3 \mathrm{n} 3$ & $0.14 \pm 0.03$ & $0.15 \pm 0.03$ & $0.17 \pm 0.11$ & $0.13 \pm 0.02$ \\
\hline C20:1n9 & $0.28 \pm 0.08$ & $0.15 \pm 0.03$ & $0.17 \pm 0.11$ & $0.13 \pm 0.02$ \\
\hline C20:4n6 & $0.18 \pm 0.03$ & $0.15 \pm 0.06$ & $0.24 \pm 0.12$ & $0.14 \pm 0.02$ \\
\hline $\mathrm{C} 20: 5 \mathrm{n} 3$ & $0.03 \pm 0.01^{b}$ & $0.14 \pm 0.04^{\mathrm{a}}$ & $0.06 \pm 0.02^{\mathrm{b}}$ & $0.13 \pm 0.02^{\mathrm{a}}$ \\
\hline C22:4n6 & $0.05 \pm 0.02^{b}$ & $0.20 \pm 0.08^{\mathrm{a}}$ & $0.10 \pm 0.08^{b}$ & $0.24 \pm 0.07^{\mathrm{a}}$ \\
\hline $\mathrm{C} 22: 6 \mathrm{n} 3$ & $0.07 \pm 0.02^{b}$ & $0.10 \pm 0.02^{\mathrm{a}}$ & $0.07 \pm 0.03^{b}$ & $0.11 \pm 0.03^{\mathrm{a}}$ \\
\hline$\Sigma$ SFA & $49.26 \pm 1.51^{\mathrm{a}}$ & $47.50 \pm 1.93^{b}$ & $51.47 \pm 1.81^{\mathrm{a}}$ & $47.79 \pm 2.40^{\mathrm{b}}$ \\
\hline$\Sigma U F A$ & $50.74 \pm 1.51^{\mathrm{b}}$ & $52.50 \pm 1.94^{\mathrm{a}}$ & $48.53 \pm 1.80^{c}$ & $52.21 \pm 2.40^{\mathrm{a}}$ \\
\hline$\Sigma$ MUFA & $47.23 \pm 1.55^{\mathrm{a}}$ & $48.33 \pm 1.53^{\mathrm{a}}$ & $45.15 \pm 1.53^{\mathrm{b}}$ & $47.37 \pm 3.04^{\mathrm{a}}$ \\
\hline$\Sigma$ PUFA & $3.79 \pm 0.41^{\mathrm{b}}$ & $4.46 \pm 1.14^{\mathrm{a}}$ & $3.68 \pm 0.61^{\mathrm{b}}$ & $5.16 \pm 1.17^{\mathrm{a}}$ \\
\hline$\Sigma \mathrm{n} 6$ & $3.28 \pm 0.45^{\mathrm{b}}$ & $3.77 \pm 1.07^{\mathrm{ab}}$ & $3.07 \pm 0.64^{\mathrm{b}}$ & $4.46 \pm 1.20^{\mathrm{a}}$ \\
\hline$\Sigma \mathrm{n} 3$ & $0.24 \pm 0.71^{\mathrm{c}}$ & $0.39 \pm 0.06^{\mathrm{a}}$ & $0.31 \pm 0.12^{\mathrm{bc}}$ & $0.38 \pm 0.06^{\mathrm{ab}}$ \\
\hline $\mathrm{n} 6 / \mathrm{n} 3$ & $15.32 \pm 5.71^{\mathrm{a}}$ & $9.41 \pm 1.99^{b}$ & $11.58 \pm 6.30^{\mathrm{ab}}$ & $12.00 \pm 3.75^{\mathrm{ab}}$ \\
\hline
\end{tabular}

SFA, saturated fatty acid; UFA, unsaturated fatty acid; MUFA, mono-unsaturated fatty acid; PUFA, poly-unsaturated fatty acid.

Values are expressed as the mean \pm standard deviation.

Different superscripts indicate significant differences $(\mathrm{a}>\mathrm{b}>\mathrm{c}, \mathrm{p}<0.05)$.

${ }^{1} \mathrm{CON}$, control; DFM-1\%, $1 \%$ direct-fed microbial supplementation; DFM+PCE-1\% and 3\%, $1 \%$ and $3 \%$ direct-fed microbial added with pine cone extract supplementation.

microbiota is associated with host energy metabolism. When lactic acid-producing bacteria is predominant, the harvesting of energy from diet increases, reducing fat deposition and regulating tissue fatty acid composition.

The $\mathrm{pH}$ of all groups of our results are slightly higher than those of $\mathrm{Ba}$ et al. (2014), who reported the $\mathrm{pH}$ values 5.43 and 5.47 for Hanwoo loin and semitendinosus muscles, respectively, and of Kim and Lee (2003), who recorded $\mathrm{pH}$ levels 5.47, 5.47, and 5.49 for Hanwoo loin grade 1, 2, and 3, respectively. There was no significant difference in WHC between the CON and DFM-1\% groups, both of which fell within the normal range as compared of $51 \%$ to $55 \%$ WHC for Hanwoo loin ascertained by Kim and Lee (2003). However, the WHC of DFM+PCE-1\% and 3\% groups were significantly lower than those of the CON and DFM-1\% groups. Apple (2007) stated that poor WHC is largely caused by pre-slaughter handling.

Hanwoo beef whose fed DFM+PCE-3\%-supplemented diet had the lowest TBARS value among the other three groups $(\mathrm{p}<0.05)$; with no significant differences in TBARS value were observed among the other three groups. Xu et al. (2012) reported that because PCE influenced on superoxide radical scavenging, it has potential as natural antioxidant agents in functional foods or medicine. Our data showed that PCE may also exhibit antioxidant properties when used as feed additives to cattle feed. A comparison to other studies is made difficult; however, by the lack of research examining the use of PCE in cattle feed.

The loin meat from Hanwoo cattle that were fed DFM supplemented diet was darker than the loin meat collected from Hanwoo cattle that were fed control diet. The presence or absence of PCE had no effect on the color differential. A slightly difference in hue angle (h) was also found; in which loin meat of Hanwoo cattle fed a DFM-supplemented diet had higher $h$ value than did control cattle. No significant difference in CIE $a^{*}$, CIE $b^{*}$, and chroma were found between $\mathrm{CON}$ and treatment groups. The instrumental color of $\mathrm{L}^{*}$ and $\mathrm{a}^{*}$ value in our results were similar to that observed by Ba et al. (2014), but the CIE b* value was lower. This might be related to different finishing diet. The CIE $\mathrm{a}^{*}$ values of all groups was regarded as grade 1 according to Kim and Lee (2003).

The WBSF values for both the DFM+PCE-1\% and 3\% groups were significantly lower $(\mathrm{p}<0.05)$ than those of CON and DFM groups. This effect is regardless the percentage of $\mathrm{DFM}+\mathrm{CPE}$ on diet. The WBSF of all groups in our study were higher than LD but similar to the semitendinosus muscle reported by $\mathrm{Ba}$ et al. (2014), and lower than that observed by Kim and Lee (2003).

The hardness (TPA) of the CON group was lower than 
that of the three treatment groups. The data suggests that supplementation with DFM+PCE-1\% and 3\% improved the texture quality of Hanwoo beef. This finding might be due to the relatively higher protein intake of DFM and DFM+PCE groups, as cattle in those groups consumed more protein, which was sourced from protein-bacteria (DFM) than did control animals. Dietary protein has been shown to influence instrumental texture variability (Marino et al., 2011). Berge et al. (1993), for instance, found that meat tenderness decreased in steers that were fed with higher protein-content diets. The loins of Hanwoo fed DFM- or DFM+PCEsupplemented diets had higher gumminess and chewiness compared to CON group ( $\mathrm{p}<0.05)$.

Palmitic and oleic acid were the primary fatty acid compounds found in the Hanwoo beef examined in the present study, a finding in accordance with that of Ba et al. (2014) who found that palmitic and oleic acid as the major fatty acid in Hanwoo. The supplementation of DFM+PCE$1 \%$ to the Hanwoo cattle's diet did not affect the composition of fatty acids, but it did lower the total unsaturated and monoUFA as compared with CON group. However, the palmitic acid (C16:0) content was decreased, whereas the stearic acid (C18:0) and other PUFAs; gamma-linolenic acid (C18:3n6), eicosapentaenoic acid (C20:5n3), adrenic acid (C22:4n6) and docosahexaenoic acid (C22:6n3), was increased in the DFM$1 \%$ and DFM+PCE-3\% compared with the CON and DFM groups $(\mathrm{p}<0.05)$. According to Wood et al. (2008), the major factor influencing the fatty acid composition of muscle in cattle is the total amount of fat in the muscle, which, in turn, the total amount of fat in muscle depends on the amount of triacylglycerols, a variable that is highly dependent on the degree of overall body fatness, the muscle type and the breed of cattle (Scollan et al., 2006).

The PUFA contents in our samples of all groups $(3.68 \%$ to $5.16 \%$ ) were higher than those reported by Panjono et al. (2011), who found $2.92 \%$ and $3.21 \%$ of PUFA of Hanwoo raised in summer and winter, respectively. The author of that study also noted that slaughter season and raising altitude affected fatty acids profiles in Hanwoo beef. The roles that genetic and nutrition play in determining relation to fatty acid composition of beef have both been widely studied, although it is generally recognized that genetic factors have less influence than do dietary factors (Scollan et al., 2006). The results showed that the highest PUFA content was found in the leanest beef from DFM+PCE-3\% group. Wood et al. (2008) mentioned that lean muscle of animals contains higher phospholipid, which has much more PUFA content than SFA.

\section{CONCLUSION}

Supplementing the diet of Hanwoo cattle with DFM resulted in beef that had higher moisture and lower fat content compared with control animals, regardless of PCE addition. Moreover, supplementing cattle diet with $\mathrm{DFM}+\mathrm{PCE}-1 \%$ and $3 \%$ tended to improve the crude protein content of the meat and lower TBARS value. The DFM supplementation on diet resulted slightly darker color and the PCE diet improved the tenderness. Supplementation with DFM+PCE-3\% is considered producing healthier Hanwoo beef loin with lower fat content and higher PUFA content than without supplementation.

\section{CONFLICT OF INTEREST}

We certify that there is no conflict of interest with any financial organization regarding the material discussed in the manuscript.

\section{ACKNOWLEDGMENTS}

This research was supported by Rural Development Administration Korea, under the grant number PJ00937201.

\section{REFERENCES}

AOAC. 2007. Official Methods of Analysis. 18th ed, Association of Official Analytical Chemists, Washington, DC, USA.

Apple, J. K. 2007. Effects of nutritional modifications on the waterholding capacity of fresh pork: A review. J. Breed. Genet. 124:43-58.

Ba, H. V., K. M. Park, D. Dashmaa, and I. Hwang. 2014. Effect of muscle type and vacuum chiller ageing period on the chemical compositions, meat quality, sensory attributes and volatile compounds of Korean native cattle beef. Anim. Sci. J. 85:164173.

Berge, P., J. Culioli, M. Renerre, C. Touraille, D. Micol, and Y. Geay. 1993. Effect of feed protein on carcass composition and meat quality in steers. Meat Sci. 35:79-92.

Choi, D. S., H. O. Jin, C. H. Lee, Y. C. Kim, and M. Kayama. 2005. Effect of Soil acidification on the growth of Korean Pine (Pinus koraiensis) seedling in a granite-derived forest soil. Environ. Sci. 12:33-47.

Costa, A. S. H., P. Costa, R. J. B. Bessa, J. P. C. Lemos, J. A. Simoes, J. Santos-Silva, C. M. G. A. Fontes, and J. A. M. Prates. 2013. Carcass fat partitioning and meat quality of Alentejana and Barrosã young bulls fed high or low maize silage diets. Meat Sci. 93:405-412.

Folch, J., M. Lees, and G. H. Sloan-Stanley. 1957. A simple method for the isolation and purification of total lipids from animal tissues. J. Biol. Chem. 226:497-509.

Grau, R. and R. A. Hamm. 1953. A simple method for the determination of water binding in muscles. Naturwissenschaften 40:29-30.

Hwang, Y. H., G. D. Kim, J. Y. Jeong, S. J. Hur, and S. T. Joo. 2010. The relationship between muscle fiber characteristics and meat quality traits of highly marbled Hanwoo (Korean native cattle) steers. Meat Sci. 86:456-461.

KAPE. 2010. Korean Beef Carcass Grading Standard. Korean 
Institute for Animal Products Quality Evaluation, Gunpo. http://www.ekape.or.kr/view/eng/system/beef.asp. Accessed September 1, 2015.

Kim, C. J. and E. S. Lee. 2003. Effects of quality grade on the chemical, physical and sensory characteristics of Hanwoo (Korean native cattle) beef. Meat Sci. 63:397-405.

Krehbiel, C. R., S. R. Rust, G. Zhang, and S. E. Gilliland. 2003. Bacterial direct-fed microbials in ruminant diets: Performance response and mode of action. J. Anim. Sci. 81:120-132.

Liu, Y., T. M. Che, M. Song, J. J. Lee, J. A. S. Almeida, D. Bravo, W. G. Van-Alstine, and J. E. Pettigrew. 2013. Dietary plant extracts improve immune responses and growth efficiency of pigs experimentally infected with porcine reproductive and respiratory syndrome virus. J. Anim. Sci. 91:5668-5679.

Marino, R., M. Albenzio, M. Caroprese, F. Napolitano, A. Santillo, and A. Braghieri. 2011. Effect of grazing and dietary protein on eating quality of Podolian beef. J. Anim. Sci. 89:3752-3758.

Musso, G., R. Gambino, and M. Cassader. 2010. Gut microbiota as a regulator of energy homeostasis and ectopic fat deposition: Mechanisms and implications for metabolic disorders. Curr. Opin. Lipidol. 21:76-83.

Panjono, S. M. Kang, I. S. Lee, and S. K. Lee. 2011. The quality characteristics of $M$. longissimus from Hanwoo (Korean cattle) steer with different raising altitudes and slaughter seasons. Livest. Sci. 136:240-246.

Sakagami, H., Y. Kawazoe, N. Komatsu, A. Simpson, M. Nonoyama, K. Konno, T. Yoshida, Y. Kuroiwa, and S. Tanuma. 1991. Antitumor, antiviral and immunopotentiating activities of pine cone extracts: Potential medicinal efficacy of natural and synthetic lignin-related materials (review). Anticancer Res. 11:881-888.

Sammel, L. M., M. C. Hunt, D. H. Kropf, K. A. Hachmeister, and D. E. Johnson. 2002. Comparison of assays for metmyoglobin reducing ability in beef inside and outside semimembranosus muscle. J. Food Sci. 67:978-984.

Scharek-Tedin, L., R. Pieper, W. Vahjen, K. Tedin, K. Neumann, and J. Zentek. 2013. Bacillus cereus var. Toyoi modulates the immune reaction and reduces the occurrence of diarrhea in piglets challenged with Salmonella Typhimurium DT104. J. Anim. Sci. 91:5696-5704.
Scollan, N., J. F. Hocquette, K. Nuernberg, D. Dannenberger, I. Richardson, and A. Moloney. 2006. Innovations in beef production systems that enhance the nutritional and health value of beef lipids and their relationship with meat quality. Meat Sci. 74:17-33

Seo, J. K., S. Kim, M. H. Kim, S. D. Upadhaya, D. K. Kam, and J. K. Ha. 2010. Direct-fed microbials for ruminant animals. Asian Australas. J. Anim. Sci. 23:1657-1667.

Sinnhuber, R. O. and T. C. Yu. 1977. The 2-thiobarbituric acid reaction, an objective measure of the oxidative deterioration occurring in fats and oil. J. Japanies Soc. Fish Sci. 26:259-267.

SPSS. 2010. Statistical Package for Social Sciences for Windows (version 19.0). SPSS Inc., Chicago, IL, USA.

Vyas, D., E. J. McGeough, S. M. McGinn, T. A. McAllister, and K. A. Beauchemin. 2014. Effect of Propionibacterium spp. on ruminal fermentation, nutrient digestibility, and methane emissions in beef heifers fed a high-forage diet. J. Anim. Sci. 92:2192-2201.

Ware, D. R., P. L. Read, and E. T. Manfredi. 1988. Pooled summary of eight feedlot trials evaluating performance and carcass characteristics of steers fed Lactobacillus acidophilus strain BT138. J. Anim. Sci. 66 (Suppl. 1):436.

Weese, J. S., S. Sharif, and A. Rodiguez-Palacios. 2008. Probiotics in veterinary medicine. In: Therapeutic Microbiology: Probiotics and Related Strategies (Eds. J. Versalovic and M. Wilson). ASM Press, Washington DC, USA. pp. 341-356.

Wood, J. D., M. Enser, A. V. Fisher, G. R. Nute, P. R. Sheard, R. I. Richardson, S. I. Hughes, and F. M. Whittington. 2008. Fat deposition, fatty acid composition and meat quality: A review. Meat Sci. 78:343-358.

Xu, R. B., X. Yang, J. Wang, H. T. Zhao, W. H. Lu, J. Cui, C. L. Cheng, P. Zou, W. W. Huang, P. Wang, W. J. Li, and X. L. Hu. 2012. Chemical composition and antioxidant activities of three polysaccharide fractions from pine cones. Int. J. Mol. Sci. 13:14262-14277.

Zerby, H. N., J. L. Bard, S. C. Loerch, P. S. Kuber, A. E. Radunz, and F. L. Fluharty. 2011. Effects of diet and Aspergillus oryzae extract or Saccharomyces cervisiae on growth and carcass characteristics of lambs and steers fed to meet requirements of natural markets. J. Anim. Sci. 89:2257-2264. 